\title{
Obstructive Uropathy Caused by Atherosclerotic Abdominal Aortic Aneurysm
}

\author{
Chia-Jung $\mathrm{Wu}^{1,3}$, Sen-Kuang Hou ${ }^{2,3}$, Chorng-Kuang How ${ }^{1,3}$ and David Hung-Tsang Yen ${ }^{1,3}$
}

Key words: aortic aneurysm, atherosclerotic aneurysm, obstructive uropathy

(Intern Med 51: 133, 2012)

(DOI: 10.2169/internalmedicine.51.6673)

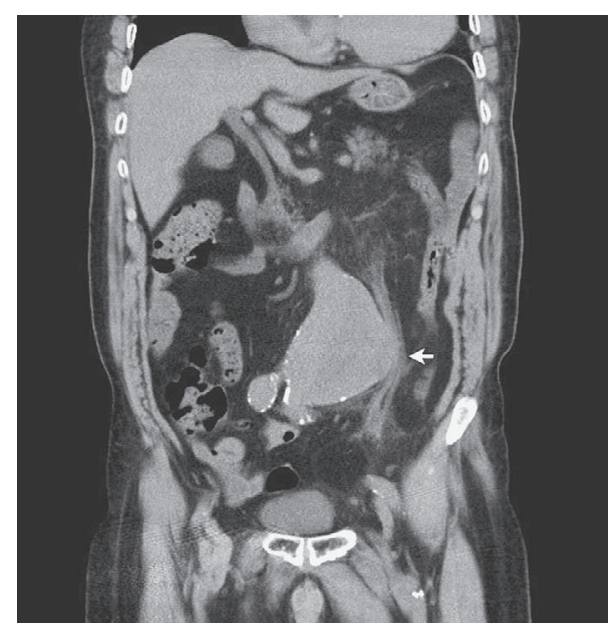

Picture 1.

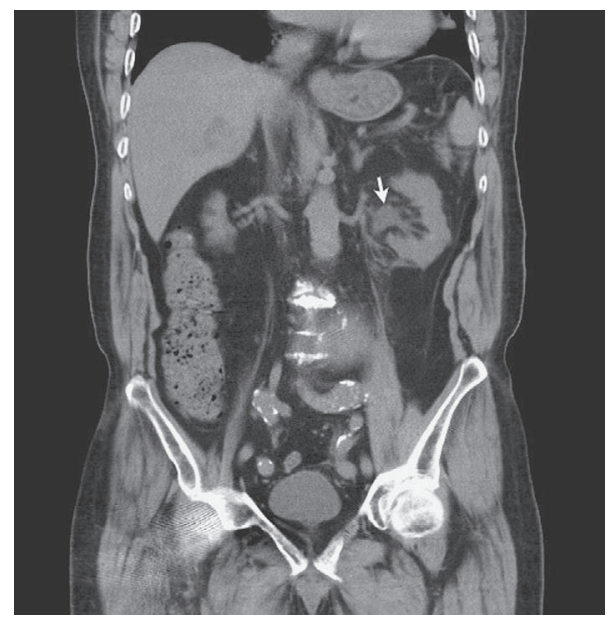

Picture 2.
A 77-year-old man with hypertension presented with left flank pain for 1 day. He was initially treated as renal colic. Due to worsening of the clinical symptoms and deteriorated renal function, a computed tomography (CT) scan was obtained which demonstrated a huge infrarenal atherosclerotic abdominal aortic aneurysm (AAA) (about $8.3 \mathrm{~cm}$ in diameter) with lateral displacement and direct extrinsic compression of the left ureter (Picture 1), causing left hydronephrosis and hydroureter (Picture 2). After endovascular aneurysm repair, he had an uneventful recovery. Follow-up studies at 16 months showed a gradual decrease of the aneurysm sac, and complete resolution of the left obstructive uropathy.

An AAA should be considered among the causes of obstructive uropathy. Most case reports are secondary to dense peri-aneurysmal fibrosis complicating inflammatory AAA, causing entrapment of the ureter within the aortic wall $(1,2)$. Atherosclerotic AAA rarely cause ureteral obstruction and lateral displacement of the ureter is a characteristic urographic finding (2).

The authors state that they have no Conflict of Interest (COI).

\section{References}

1. Speziale F, Sbarigia E, Grossi R, Maraglino C, Fiorani P. Inflammatory aneurysms of the abdominal aorta involving the ureters: is combined treatment really necessary? J Urology 165: 27-31, 2001.

2. Sánchez R, Arroyo A, Gesto R, Fernández-Reyes MJ, Mon C, Alvarez-Ude F. Obstructive ARF caused by an inflammatory abdominal aortic aneurysm. Am J Kidney Dis 41: e9, 2003.

\footnotetext{
${ }^{1}$ Emergency Department, Taipei Veterans General Hospital, Taiwan, ${ }^{2}$ Emergency Department, National Yang-Ming University Hospital, Taiwan and ${ }^{3}$ National Yang-Ming University School of Medicine, Taiwan

Received for publication October 4, 2011; Accepted for publication October 11, 2011

Correspondence to Dr. Chorng-Kuang How, ckhow@vghtpe.gov.tw

(C) 2012 The Japanese Society of Internal Medicine Journal Website: http://www.naika.or.jp/imindex.html
} 